\title{
Knowledge of Health Workers in Public Health Centers of the Health District of Lomé Commune on Dengue
}

\author{
Lidaw Deassoua Bawe ${ }^{1 *}$, Akouda Akessiwe Patassi ${ }^{1}$, Awereou Kotosso ${ }^{1,2}$, \\ Bawoubadi Abaltou' ${ }^{1,2}$, Abdou-Razak Moukaïla1, Dosseh Dandogan', Majeste Ihou Wateba1
}

${ }^{1}$ Department of Infectious and Tropical Diseases, Sylvanus Olympio Teaching Hospital, Lomé, Togo

${ }^{2}$ Army Hospital of Lomé, Lomé, Togo

Email: *alainbawe@yahooo.fr

How to cite this paper: Bawe, L.D., Patassi, A.A., Kotosso, A., Abaltou, B., Moukaïla, A.-R., Dandogan, D. and Wateba, M.I. (2021) Knowledge of Health Workers in Public Health Centers of the Health District of Lomé Commune on Dengue. Advances in Infectious Diseases, 11, 430-440. https://doi.org/10.4236/aid.2021.114038

Received: November 12, 2021

Accepted: December 21, 2021

Published: December 24, 2021

Copyright $\odot 2021$ by author(s) and Scientific Research Publishing Inc. This work is licensed under the Creative Commons Attribution-NonCommercial International License (CC BY-NC 4.0). http://creativecommons.org/licenses/by-nc/4.0/ cc) (1) (8) Open Access

\begin{abstract}
Background: Dengue is under-reported in the indicators and directories of health statistics in Togo and the diagnostic hypothesis of dengue during medical consultations is often not mentioned. Objective: The objective is to assess healthcare workers' knowledge of dengue and its management in public health centers in the health district of Lomé Commune. Materials and Methods: This is a cross-sectional and descriptive study that took place from November 1, 2019 to February 29, 2020 in the health district of Lomé Commune. Results: This study involved 280 healthcare workers out of 310 concerned, i.e., a participation rate of $90.32 \%$, distributed over the 22 public health centers of the health district of Lomé Commune. The age of the healthcare workers ranged from 18 to 58 years with an average age of 33 years $( \pm 8.14)$. The age group [ 25 - 35 years] was more represented with $53.20 \%$. Physicians were more represented with $46.07 \%$. The majority of healthcare professionals were aware of the existence of dengue (90.36\%). The essential clinical signs were more or less known, especially by the physicians. Dengue hemorrhagic fever was the most known clinical form and represented $70 \%$. Treatment was symptomatic according to the majority (63.21\%) and was based on analgesics (71.43\%) and antipyretics (65\%). The existence of a vaccine is not well known and represented $16.79 \%$; the use of impregnated mosquito net is more cited as a secondary means of prevention, $77.86 \%$. Conclusion: Dengue is not well known by the health professionals involved in the survey. Nevertheless, physicians have a more or less good knowledge compared to paramedics. In practice, the diagnosis of dengue is often not mentioned.
\end{abstract}

\section{Keywords}

Dengue, Knowledge, Healthcare Worker, Lomé Commune, Togo 


\section{Introduction}

Dengue or tropical influenza is currently the main arbovirus of the tropical regions surrounding the globe [1] and is one of the neglected tropical diseases, constituting a major public health concern [2].

Arboviruses are zoonotic diseases usually transmitted from vertebrate to vertebrate via a hematophagous arthropod, which is most often a mosquito or a tick [1] [3]. A modeling estimates indicate that 390 million dengue virus infections occur annually, of which 96 million are clinically manifested (all severities) [4]. Over the past two decades, the number of dengue cases reported to WHO has increased more than eightfold, from 505,430 cases in 2000 to 4.2 million cases in 2019 [4]. Most infections are encountered in urban areas in tropical and subtropical regions, but imported dengue cases have been reported in non-tropical regions [5]. In Africa, the incidence of dengue is largely unknown due to poor surveillance and non-reporting of cases and epidemics to WHO [6].

In Togo, the first cases of dengue were reported between the years 1987 and 2000 in expatriate travelers after a stay in Togo without identification of the serotype involved [7]. In 2017, a few cases of dengue were identified and confirmed by the National Institute of Hygiene according to the Ministry of Health without any recorded deaths [8]. Two studies were conducted at the Sylvanus Olympio Teaching Hospital in 2017; one about 2 hospitalized cases of dengue hemorrhagic fever and the other concerned the search for NS1-Dengue antigen in febrile patients [9] [10]. Dengue is under-reported or almost not reported in the indicators and directories of health statistics in Togo. Moreover, the diagnostic hypothesis of dengue during medical consultations is often not mentioned. It is in this perspective that the said study was initiated in order to evaluate the knowledge of healthcare staff on this plague in order to participate in its elimination.

The main objective of this study was to evaluate the knowledge of healthcare workers on dengue and its management in the public health centers of the health district of Lomé commune.

\section{Material and Methods}

This is a descriptive and cross-sectional study from November 1, 2019 to February 29, 2020 concerning healthcare workers providing medical consultation in public health facilities in the health district of Lomé Commune. It involved general practitioners and specialists, medical assistants, nurses, midwives and birth attendants practicing in the infectious diseases, medical emergencies, internal medicine, general medicine, maternity and pediatrics departments of the Teaching Hospitals, district hospitals and medico-social centers of the health district of Lomé Commune.

The health district of Lomé commune has five health districts composed of public, private and religious healthcare facilities. The public healthcare facilities are composed of 2 Teaching Hospitals (CHU), 1 Regional Hospital (CHR), 5 
District Public Hospitals (HD), 13 Public Socio-Medical Centers (CMS) and 1 polyclinic.

All healthcare workers working in the public health facilities of the health district of Lomé commune, who were present on the day of the survey and who agreed to participate in the study were included.

The sampling was exhaustive and the total number of healthcare workers who participated in the study was 280 , excluding those on leave, healthcare workers on administrative leave and those not available.

The data were collected through an anonymous questionnaire with closed and open questions given to each healthcare worker and filled in immediately after an explanation of the study objectives. The variables studied were sociodemographic (age, sex, occupation, professional experience), epidemiological (causal agent and mode of transmission), clinical (clinical signs, clinical forms, complications and differential diagnosis), biological (referral and confirmatory biological tests for dengue) and therapeutic. For reliability and validity of the questionnaire, a pre-test was conducted on a small sample of healthcare workers in a health facility outside the study area.

The level of knowledge was judged as good, average or poor. Knowledge was good when the percentage of correct answers obtained was $\geq 80 \%$; knowledge was average when the percentage of correct answers was between $50 \%$ and $79 \%$, and poor when the percentage was $<50 \%$.

The Chi-square $\left(\chi^{2}\right)$ test was the primary statistical test used for categorical variables of interest at the $95 \%$ significance level. The significance level was set at $5 \%$.

Participation in the study required informed verbal consent and did not require any compensation since the voluntary nature of the study was emphasized. The directors of the various health districts were informed by a request through the hierarchy and gave their agreement by memos to the various healthcare facilities to be surveyed in their health area.

\section{Results}

The participation rate was $90.32 \%$, i.e., 280 healthcare workers surveyed out of 310 in 22 public health facilities in the health district of Lomé Commune.

\subsection{Socio-Professional Characteristics}

The median age was 30 years $( \pm 12)$ and the age group [25 - 45 years] represented $74.60 \%$. Medical staff (physicians and medical assistants) were in the majority as was professional experience ranging from 0 to 10 years for most (Table 1 ).

\subsection{General Knowledge about Dengue}

Knowledge about the existence of dengue, the causative agent and the means of transmission

Dengue was known by the majority of healthcare workers (90.36\%). Medical 
school training and media information were the most cited sources of knowledge about dengue. More than half of the healthcare workers (54.29\%) knew that dengue is caused by a virus and $81.79 \%$ also knew the means of transmission due to mosquito bite. There was a significant difference in the knowledge of the existence, causative agent and mode of transmission of dengue among the different professional categories $(\mathrm{p}<0.001)$. Physicians are more familiar with the existence of the disease and its causative agent and mode of transmission than paramedics (Table 2).

\section{Knowledge about clinical signs}

Headache (80.36\%), fever (80.00\%), arthralgia (63.57\%), myalgia (61.07\%), hemorrhagic manifestations (50.71\%) were the clinical signs most cited by the healthcare workers with a significant difference (Table 3).

\section{Knowledge about clinical forms}

Dengue hemorrhagic fever was mentioned in $70.00 \%$ of cases, followed by classical dengue (61.43\%). And dengue with shock syndrome $(41.43 \%)$, there was a significant difference in knowledge about clinical forms $(\mathrm{p}<0.05)$.

Table 1. Distribution of healthcare workers in public health centers in the health district of Lomé Commune according to socio-professional characteristics.

\begin{tabular}{|c|c|c|}
\hline & Number (n) & Percentage (\%) \\
\hline \multicolumn{3}{|l|}{ Gender } \\
\hline Male & 142 & 50.71 \\
\hline Female & 138 & 49.29 \\
\hline Total 1 & 280 & 100 \\
\hline \multicolumn{3}{|l|}{ Age } \\
\hline$\leq 25$ years & 42 & 10.40 \\
\hline$[26-45$ years $]$ & 209 & 74.60 \\
\hline [46 - 60 years] & 29 & 15.00 \\
\hline Total 2 & 280 & 100 \\
\hline \multicolumn{3}{|l|}{ professionnal Category } \\
\hline General Practitioner & 110 & 39.29 \\
\hline Specialist & 19 & 06.78 \\
\hline Medical Assistant & 35 & 12.50 \\
\hline Nurse & 45 & 16.79 \\
\hline Midwife/Birth Attendant & 71 & 25.36 \\
\hline Total 3 & 280 & 100 \\
\hline \multicolumn{3}{|l|}{ Work Experience } \\
\hline [0 - 10 years $]$ & 211 & 75.35 \\
\hline [11 - 20 years] & 51 & 18.22 \\
\hline$>20$ years & 18 & 06.43 \\
\hline Total 4 & 280 & 100 \\
\hline
\end{tabular}


Table 2. Distribution of healthcare workers in the public health centers of the health district of Lomé Commune according to their knowledge of the existence of dengue, the causal agent and the mode of transmission.

\begin{tabular}{|c|c|c|c|}
\hline Awareness of the existence of dengue & Yes & No & Total \\
\hline Physician & $129(100.00 \%)$ & $00(0.00 \%)$ & 129 \\
\hline Medical Assistant & $33(94.29 \%)$ & $02(05.71 \%)$ & 35 \\
\hline Nurse & $40(88.89 \%)$ & $05(11.11 \%)$ & 45 \\
\hline Midwife/Birth Attendant & $51(71.83 \%)$ & $20(28.17 \%)$ & 71 \\
\hline Total 1 & $253(90.36 \%)$ & $27(09.64 \%)$ & 280 \\
\hline Knowledge about the causative agent & Good answer & Bad answer & Total \\
\hline Physician & $89(68.99 \%)$ & $40(31.01 \%)$ & 129 \\
\hline Medical Assistant & $20(57.14 \%)$ & $15(42.86 \%)$ & 35 \\
\hline Nurse & $22(48.89 \%)$ & $23(51.11 \%)$ & 45 \\
\hline Midwife/Birth Attendant & $21(29.58 \%)$ & $50(70.42 \%)$ & 71 \\
\hline Total 2 & $152(54.29 \%)$ & $128(45.71 \%)$ & 280 \\
\hline Knowledge about the means of transmission & Good answer & Bad answer & Total \\
\hline Physician & $123(95.35 \%)$ & $06(04.65 \%)$ & 129 \\
\hline Medical Assistant & $31(88.57 \%)$ & $21(45.32 \%)$ & 47 \\
\hline Nurse & $35(77.78 \%)$ & $10(22.22 \%)$ & 45 \\
\hline Midwife/Birth Attendant & $40(56.34 \%$ & $31(43.66 \%$ & 71 \\
\hline Total 3 & $229(81.79 \%)$ & $51(18.21 \%)$ & 280 \\
\hline
\end{tabular}

Table 3. Distribution of healthcare workers in public health centers in the health district of Lomé Commune according to their knowledge about the clinical signs of dengue.

\begin{tabular}{|c|c|c|c|c|c|c|c|c|c|}
\hline & Headache & Fever & Arthralgia & Myalgia & $\begin{array}{c}\text { Nausea and } \\
\text { vomiting }\end{array}$ & $\begin{array}{l}\text { Hemorrhagic } \\
\text { manifestation }\end{array}$ & Skin rash & $\begin{array}{c}\text { Low Back } \\
\text { Pain }\end{array}$ & Don't know \\
\hline Physician & $\begin{array}{c}123 \\
(95.35 \%)\end{array}$ & $\begin{array}{c}124 \\
(96.12 \%)\end{array}$ & $\begin{array}{c}112 \\
(86.82 \%)\end{array}$ & $\begin{array}{c}99 \\
(7674 \%)\end{array}$ & $\begin{array}{c}84 \\
(65.12 \%)\end{array}$ & $\begin{array}{c}99 \\
(76.74 \%)\end{array}$ & $\begin{array}{c}90 \\
(69.77 \%)\end{array}$ & $\begin{array}{c}35 \\
(27.13 \%)\end{array}$ & $\begin{array}{c}06 \\
04.65 \%)\end{array}$ \\
\hline $\begin{array}{l}\text { Medical } \\
\text { Assistant }\end{array}$ & $\begin{array}{c}29 \\
(82.86 \%)\end{array}$ & $\begin{array}{c}29 \\
(82.86 \%)\end{array}$ & $\begin{array}{c}24 \\
(68.57 \%)\end{array}$ & $\begin{array}{c}25 \\
(71.43 \%)\end{array}$ & $\begin{array}{c}17 \\
(48.57 \%)\end{array}$ & $\begin{array}{c}11 \\
(48.57 \%)\end{array}$ & $\begin{array}{c}16 \\
(45.71 \%)\end{array}$ & $\begin{array}{c}06 \\
(17.14 \%)\end{array}$ & $\begin{array}{c}09 \\
(25.71 \%)\end{array}$ \\
\hline Nurse & $\begin{array}{c}34 \\
(75.56 \%)\end{array}$ & $\begin{array}{c}35 \\
(77.78 \%)\end{array}$ & $\begin{array}{c}22 \\
(48.89 \%)\end{array}$ & $\begin{array}{c}25 \\
(55.56 \%)\end{array}$ & $\begin{array}{c}23 \\
(51.11 \%)\end{array}$ & $\begin{array}{c}16 \\
(35.56 \%)\end{array}$ & $\begin{array}{c}16 \\
(35.56 \%)\end{array}$ & $\begin{array}{c}13 \\
(28.89 \%)\end{array}$ & $\begin{array}{c}16 \\
(36.56 \%)\end{array}$ \\
\hline Midw/BA & $\begin{array}{c}39 \\
(55.00 \%)\end{array}$ & $\begin{array}{c}36 \\
(50.70 \%)\end{array}$ & $\begin{array}{c}20 \\
(28.17 \%)\end{array}$ & $\begin{array}{c}22 \\
(31.00 \%)\end{array}$ & $\begin{array}{c}19 \\
(26.76 \%)\end{array}$ & $\begin{array}{c}16 \\
(22.53 \%)\end{array}$ & $\begin{array}{c}16 \\
(22.53 \%)\end{array}$ & $\begin{array}{c}10 \\
(14.08 \%)\end{array}$ & $\begin{array}{c}40 \\
(56.34 \%)\end{array}$ \\
\hline Total & $\begin{array}{c}225 \\
(80.36 \%)\end{array}$ & $\begin{array}{c}224 \\
(80.00 \%)\end{array}$ & $\begin{array}{c}178 \\
(63.57 \%)\end{array}$ & $\begin{array}{c}171 \\
(61.07 \%)\end{array}$ & $143(51.07 \%)$ & $\begin{array}{c}138 \\
(49.29 \%)\end{array}$ & $\begin{array}{c}138 \\
(49.29 \%)\end{array}$ & $\begin{array}{c}64 \\
(22.86 \%)\end{array}$ & $\begin{array}{c}71 \\
(25.36 \%)\end{array}$ \\
\hline $\mathbf{P}$ & $<0.001$ & $<0.001$ & $<0.001$ & $<0.001$ & 0.056 & $<0.001$ & $<0.001$ & 0.188 & $<0.001$ \\
\hline
\end{tabular}

Midw = midwife; $\mathrm{BA}=$ Birth Attendant.

\section{Knowledge of confirmatory biological tests}

Over the 280 healthcare workers, 205 (73.21\%) were aware that the confirmatory diagnosis of dengue is provided by RT-PCR and serology with higher rates among medical staff (Physicians and medical assistants, $\mathrm{n}=164)$ or $90.24 \%(\mathrm{n}=$ 
148). There was a significant difference in knowledge of confirmatory biological tests $(\mathrm{p}<0.001)$.

\section{* Knowledge about dengue treatment}

Medical staff knew that treatment of dengue is symptomatic in the majority of cases. There was a significant difference in knowledge about the type of treatment ( $\mathrm{p}<0.001)$ (Table 4).

Analgesics (71.43\%), antipyretics (65\%) and bed rest (48.21\%) were the most cited means of symptomatic treatment with a significant difference in knowledge of analgesics and antipyretics $(\mathrm{p}<0.05)$.

\section{* Knowledge of dengue prevention}

The existence of a vaccine against dengue was known by only $16.79 \%$ of the healthcare workers.

Other means of dengue prevention were well known in the majority of cases with a significant difference $(\mathrm{p}<0.05)$ : sleeping under a mosquito net $(77.86 \%)$; destruction of larval breeding sites (73.21\%); use of repellent cream (57.50\%).

\section{Discussion}

\subsection{Socio-Professional Characteristics}

Healthcare professionals in Togo are relatively young as shown by the median age and their work experience of this study. This finding was made in Tanzania where a similar study conducted on the issue found that the majority of healthcare professionals $(n=86)$ were between 25 and 40 years old $(48 \%)$ with work experience ranging from 0 to 10 years for most $(n=62)$ [11]. The predominance of paramedics was also noted in Burkina Faso (89\% nurses) [12] and Tanzania (75.3\% nurses) [11]. Paramedics still make up the majority of the health workers in Togo for several reasons. The country has several training schools for medical assistants and midwives. In addition, in peripheral health facilities outside hospitals, paramedics are the first actors who play the role of physician.

Table 4. Distribution of healthcare workers in public health centers in the health district of Lomé Commune according to knowledge about the type of dengue treatment.

\begin{tabular}{ccccc}
\hline & Symptomatic treatment & Curative treatment & Symptomatic and curative Treatments & Don't know \\
\hline Physician & 112 & 03 & 05 & 09 \\
& $(86.82 \%)$ & $(02.33 \%)$ & $(03.88 \%)$ & $(06.98 \%)$ \\
Medical Assistant & 25 & 00 & 06 & 04 \\
Nurse & $(71.43 \%)$ & $(00.00 \%)$ & $(17.14 \%)$ & $(11.43 \%)$ \\
& 22 & 01 & 09 & $(28.89 \%)$ \\
Midw/BA & $(48.89 \%)$ & $(02.22 \%)$ & $(20.00 \%)$ & 35 \\
& 18 & 4 & 14 & $(49.30 \%)$ \\
Total & $(25.35 \%)$ & $(5.63 \%)$ & $(19.72 \%)$ & $\mathbf{6 1}$ \\
& $\mathbf{1 7 7}$ & $\mathbf{0 8}$ & $(\mathbf{1 2 . 1 4 \% )}$ & $(21.79 \%)$ \\
\hline
\end{tabular}

Midw = midwife; $\mathrm{BA}=$ Birth Attendant. 


\subsection{General Knowledge about Dengue}

Dengue is known to most healthcare workers as a viral infectious disease and its means of transmission; however, the causal agent, which is a virus, was not well known among physicians. Sondo et al. in Burkina Faso had reported a high proportion of knowledge of dengue but $62.50 \%$ for knowledge about the causal agent [12]. In Tanzania, according to Kajeguka et al. the majority of healthcare professionals knew about dengue through the media [11]. The fact that malaria and dengue are transmitted by mosquito bite may be confusing for some who are unaware that dengue is caused by a virus. The level of knowledge is not the same among all caregivers. Physicians had a much higher level of knowledge than other socio-professional categories with a significant difference $(p<0.05)$. The level of study of physicians is in favor of their better knowledge of the disease, especially since the teaching modules are not the same with paramedics.

The clinical signs of dengue were well known among physicians and medical assistants who have better knowledge because they are the ones who often provide consultations in healthcare facilities. A few years ago, a study on the detection of dengue in consultations conducted by the National Institute of Hygiene in certain health centers in the city of Lomé also enabled this good knowledge of clinical signs similar to malaria. Dengue hemorrhagic fever is the most frequently cited clinical form and this is also explained by the fact that dengue is known by most healthcare professionals as viral hemorrhagic fever.

Confirmatory tests for dengue such as molecular biology and serology are better known in Burkina Faso (71.10\%) [12] and Guadeloupe (75\%) [13]. Medical staff (especially physicians) are more familiar with these additional confirmatory examinations compared to other professional categories, thanks to the teaching of this pathology at the faculty of medicine. The rates are higher in Sondo et al. in Burkina Faso (71.10\%) [12] and in Hélène-Pélage et al. in Guadeloupe (75\%) [13]. Molecular biology is indeed a new or difficult term for paramedics to understand, especially if it was never covered during their training. In reality, paramedics, especially nurses, are trained to provide nursing care and midwives are trained to monitor pregnancy, delivery and post-partum. They are not trained to diagnose pathologies like my doctors. It is the lack of doctors that causes some paramedics to substitute for doctors in some health facilities.

\subsection{Knowledge of Dengue Treatment and Prevention}

It is well known among healthcare providers that most viral diseases such as dengue are managed symptomatically, which explains the high use of analgesics/antipyretics (81.3\%) in a study in Burkina Faso [12]. This high level of use is explained by the fact that signs such as fever, headaches, aches and pains and diffuse pain are in the foreground; in addition, analgesics and antipyretics are widely used in the treatment of febrile diseases. In general, anti-inflammatory drugs were less used and the avoidance of Aspirin and Ibuprofen were mentioned in Guadeloupe [13]. This proves that the majority of caregivers are aware 
that anti-inflammatory drugs increase the risk of aggravating the inflammatory reaction in viral pathologies and should be avoided as much as possible.

In terms of prevention, the existence of a vaccine against dengue is not well known among healthcare workers, because the vaccine is not widely used and because of its recent development. As the means of transmission of dengue is similar to that of malaria, other means of prevention have been well reported in our series and in Burkina Faso in high proportions [12].

The limitations of this study are that the administration of the questionnaire was not straightforward because of the workload. This situation required the interviewer to distribute the questionnaire to staff and return on another day to collect the completed questionnaire. This certainly allowed some of the respondents to go and get the answers to the questions. As a result, the actual assessment of knowledge may be biased.

\section{Conclusions}

Dengue is the most common arbovirus in the world and is considered by the World Health Organization to be an emerging disease in urban areas of tropical and subtropical regions.

This study reveals that healthcare workers in public health centers in the health district of Lomé Commune do not have good knowledge of dengue. However, this knowledge is better among physicians than among other socio-professional categories. In practice, the diagnosis or assumption of dengue is often not made, considering that dengue is relatively rare due to the absence of an epidemic in the country. Malaria is over-treated in cases of fever and cases of classical dengue would be treated as malaria. However, caution is required to diagnose severe dengue cases early and to identify outbreaks.

At the end of this study, we suggest the recommendation to the nursing staff to think of dengue during medical consultations or in case of febrile episode and especially to ask for complementary examination for its confirmation.

\section{Conflicts of Interest}

The authors declare no conflicts of interest regarding the publication of this paper.

\section{References}

[1] Diallo, I., Sondo, K.A., Tieno, H., Tamelokpo, E.Y., Zoungrana, J., Diendéré, E.A., et al. (2017) À propos de 98 cas de dengue hospitalisés dans une clinique privée de Ouagadougou: aspects épidémiologiques, diagnostiques et évolutifs. Bulletin de la Société de Pathologie Exotique, 110, 291-296. https://doi.org/10.1007/s13149-017-0585-7

[2] CMIT (2012) Arbovirose. In: Pilly, E., Ed., Maladies Infectieuses et tropicales, Collège des Universitaires de Maladies Infectieuses et Tropicales, Paris, 418-419.

[3] World Health Organization (2009) Dengue Guidelines for Diagnosis, Treatment, Prevention and Control: New Edition. World Health Organization, Geneva, 147 p. 
[4] Organisation Mondiale de la Santé (2020) Dengue et dengue sévère. Organisation Mondiale de la Santé, Genève.

[5] Faye, O., Ba, Y., Faye, O., Talla, C., Diallo, D., Mondo, M., et al. (2014) Urban Epidemic of Dengue Virus Serotype 3 Infection, Senegal, 2009. Emerging Infectious Diseases, 20, 456-459. https://doi.org/10.3201/eid2003.121885

[6] Gubler, D.J. and Kuno, G. (1997) Dengue and Dengue Hemorrhagic Fever. CAB International, New York, $477 \mathrm{p}$.

[7] Amarasinghe, A., Kuritsk, J.N., Letson, G.W. and Margolis, H.S. (2011) Dengue Virus Infection in Africa. Emerging Infectious Disease, 17, 1349-1354. https://doi.org/10.3201/eid1708.101515

[8] Ministère de la Santé et de la Protection Sociale (2017) Apparition de la dengue: le ministre de la santé rassure les populations. Portail officiel de la République togolaise.

[9] Salou, M., Zida-Compaoré, W.I.K., Gbéassor-Komlanvi, F.A., Folly-Gbogboè, M., Konou, A.A., Dossim, S., Mama, Z., Douffan, M., Ekouévi, D.K. and Dagnra, A.Y. (2021) Prévalence de la dengue chez les patients présentant un syndrome fébrile au Centre Hospitalier Universitaire SylvanusOlympio de Lomé (Togo) en 2017. MTSI, 1, No. 4. https://doi.org/10.48327/mtsi.2021.183

[10] Watéba, I.M., Bawé, L.D., Patassi, A.A., Kotosso, A., Balaka, A., Abaltou, B., et al. (2018) Dengue hémorragique: à propos de 2 cas observés dans le service des Maladies Infectieuses et Tropicales du CHU Sylvanus Olympio, Lomé (Togo). Revue Tunisienne d Infectiologie, 12, 1-4.

[11] Kajeguka, D.C., Desrochers, R.E., Mwangi, R., Mgabo, M.R., Alifrangis, M., Kavishe, R.A., Mosha, F.W. and Kulkarni, M.A. (2017) Knowledge and Practice Regarding Dengue and Chikungunya: A Cross-Sectional Study among Healthcare Workers and Community in Northern Tanzania. Tropical Medicine and International Health 22, 583-593. https://doi.org/10.1111/tmi.12863

[12] Sondo, K.A., Diendéré, E.A., Diallo, I., Zoungrana, J., Poda, A., Sawadogo, M., et al. (2018) Connaissance des agents de santé sur la prise en charge de la dengue à Ouagadougou (Burkina Faso). Journal de la Recherche Scientifique de I'Université de Lomé, 41, 17-29.

[13] Hélène-Pélage, J. and Zami-Rinaldo, F. (2005) Connaissances et attitudes pratiques des médecins généralistes guadeloupéens: à propos des dengues sévères. Médecine et Maladies Infectieuses, 35, S67-S68. https://doi.org/10.1016/S0399-077X(05)80884-4 


\section{Appendix}

Knowledge of healthcare workers on the management of dengue in the health district of

Lomé commune (Togo)

Survey form

I. Socio-professional characteristics

1. Age: / _ /

2. Sex: / I

3. Occupation: Physician / _ / Physician's Assistant /_ / Nurse /_ / Midwife / _ / Birth attendant / _ / If Physician: Specialist / _ / General Practitioner /

4. Year of service: / _ /

5. Workplace: CHU / _ / CHR / _ / DISTRICT HOSPITAL / _ / CMS / _ / USP I_l

\section{General knowledge of dengue}

5. Have you ever heard of dengue fever? Yes / _ / No / _ /

If Yes Media / _ / Medical schools / _ / Training institute / _ / Workplace / _ I From a colleague /_ I

6. What is the causative agent of dengue fever?

Don't know / _ / Parasite / _ / Fungus / _ / Bacteria / _ / Virus / _ /

7. What is the mode of transmission of dengue fever?

Mosquito bite /_ / Sexual intercourse / _ / Dirty hands /_ / Oral / _ / Flies / _ I Don't know /_/

8. Name the clinical signs of dengue

Headache / _ Retro-orbital pain / _ / Abdominal pain / _ / Myalgias / _ / Arthralgias / _ / Skin rash / _ / Shock syndrome / _ / Bleeding manifestations / _ I fever / _ / nausea / _ / vomiting / _ / don't know / _ /

9. Name the clinical forms of dengue

Classic dengue / _ / Hemorrhagic dengue / _ / Dengue with shock syndrome / _ / Don't know / _ /

10. Name the biological tests used to diagnose dengue fever Dengue serology /_ / RT-PCR Dengue /_/Blood Test /_ / CBC / _ / Transaminases / _ / CRP / _ / Blood culture / _ / PT / _ / SV / _ / Don't know / _ /

11. Confirmatory biological tests for dengue: Serology / _ / RT-PCR / _ / Don't know / _ /

12. Name the complications of dengue fever: Hemorrhage / _ / Shock syndrome / _ / Cardiovascular collapse / _ / Death / _ / Don't know / _ /

\section{Differential diagnosis}

What diseases should not be confused with dengue fever?

Malaria / _ / Typhoid fever / _ / Yellow fever / _ / Meningitis / _ Ebola / _ I Sepsis /_ / Leptospirosis /_ / Influenza /_ / Chikungunya / _ / Zika / _ / Eruptive fevers / _ / Infectious mononucleosis / _ / Cytomegalovirus / _ / Other hemorrhagic fevers / _ / Don't know / _ / Other:

14. Is the treatment for dengue fever Symptomatic / _ / Curative / _ / Symp- 
tomatic and Curative / $/$ ?

15. Name the means of treatment for dengue fever

Anti-inflammatory / _ / Antibiotic / _ / Analgesic / _ /

Antihistamines / _ / Bed rest / _ / Antiviral / _ / Blood transfusion / _ / Plenty of fluids / _ / Anti-malarial /_ / Antipyretic / _ / Don't know / _ /

16. How to prevent dengue fever?

Sleeping under mosquito net / _ / Use repellent creams / _ / _ / Vaccination / / Destruction of mosquito breeding grounds / _ / Don't know / _ /

Others: 